\title{
Homeless Family Shelters and Family Homelessness
}

\author{
GORDON BERLIN \\ Manpower Demonstration Research Corporation \\ WILLIAM McALLISTER
}

City University of New York

One of the more valuable contributions of Peter Rossi's article is to remind us of the critical role that shelters play in defining and responding to the problem of homeless families. As Rossi points out, shelters help form our conceptualization of the problem-what kinds of families are homeless and why as well as their number.

Perhaps more important, increasingly sophisticated shelters have come to define our policy response to family homelessness. Rossi reports that the number of family shelters soared throughout the middle and late 1980s and that they changed from simply providing a roof and food in an emergency to also providing social, medical, and psychological services for longer periods in more private quarters. And the future promises much more of the same. If the Department of Housing and Urban Development (HUD) follows the suggestions its Assistant Secretary for Community Planning made for New York City, the Clinton homeless family policy will likely center around shelters (New York Commission on the Homeless, 1992). ${ }^{1}$

Here we want to extend Rossi's emphasis on the role of shelters in dealing with family homelessness. We make two arguments. One, shelters define the problem of family homelessness and therefore a particular conception of that problem. Two, shelters act to select from the population of poor families those who are worst off in some ways (housing, income, managing their lives, drug or alcohol addictions) and least able or willing to cope with circumstances other poor families do handle. ${ }^{2}$ We then explain that one reason why shelters play this role is because the ratio of "worst off, least able" poor families to the total number of poor families is so small that a device is needed to identify these families. ${ }^{3}$ Shelters are such a device.

In the final section, we fill a lacuna in Rossi's causal analysis with a few ideas as to why shelter growth exploded in the mid-1980s and we explain our disagreement with Rossi's major policy suggestions. Because shelters house

Authors' Note: We thank Jennifer Parker for her comments.

AMERICAN BEHAVIORAL SCIENTIST, Vol. 37 No. 3, January $1994422-434$

(C) 1994 Sage Publications, Inc.

422 
such a small proportion of all poor families and because few families stay sheltered very long, Rossi's recommendations are a very inefficient way to end homelessness. Also, the amounts of money entailed in his proposals are so large they are unlikely to be appropriated; and if lesser amounts are appropriated, they are unlikely, absent targeting, to reach families apt to become homeless.

\section{USING SHELTERS TO DEFINE FAMILY HOMELESSNESS}

As far as government and the public are concerned, family homelessness exists only insofar as there are homeless family shelters (dormitory facilities, hotels and motels, or other quarters designated a family shelter by its funding source or political purpose). That is, family homelessness is by definition almost entirely a "construction" of the shelter system (to use Rossi's phrase). ${ }^{4} \mathrm{We}$ conclude there is a problem because we have shelters that house families for months or years. We presume to understand the characteristics of homeless families and why they become homeless because we know the attributes and stories of family in homeless shelters. We claim to know the size of the homeless family problem and its growth rate when we measure the number of families living in shelters. And we will think the problem is declining if the number of sheltered families decreases. If all family shelters were to close tomorrow, the homeless family problem would largely disappear from government budgets and from the public agenda.

We are not saying the problems these families experience would go away. They would remain, of course, and some families would get treated elsewhere in the social service or subsidized housing systems and their problems would be called something besides homelessness. But their problems would become more hidden from the public, and many families now assisted by government money would be helped less or not at all.

We can see that homeless family shelters construct the problem of family homelessness by contrasting how families become identified as homeless with how single adults are so identified. Whether single men and women are labeled "homeless" by the government or the public does not depend on the existence of shelters. Single people can and do become homeless by living on the street; homeless families can, of course, but do not. They become a homeless family by entering a shelter. ${ }^{5}$

One has to have some definition of homelessness for it to exist. But as Herbert Blumer (1971) points out, "Social problems are fundamentally products of a process of collective definition instead of existing independently as a set of objective social arrangements with an intrinsic makeup" (p. 198). Since shelters define family homelessness, what we think constitutes homelessness and what we think are the problems of poor families who are relatively worse off will be functions of the kinds of families that use shelters. Homeless family shelters create $a$ construction of some problems experienced by poor families. 
The families entering a shelter, for example, not only may have housing conditions that are more harsh than most poor families but perhaps worse social, medical, or psychological problems as well (Knickman \& Weitzman, 1989). And families that remain sheltered (i.e., that dominate the work of shelters) probably have even more severe versions of these problems (Bassuk \& Rosenberg, 1988). ${ }^{6}$ If we rely on shelters to define family homelessness, we may think the problem has a lot to do with a mother's drug or alcohol addictions, her psychological problems, or her inability to manage money, children, and a home. This is what medical, social service, and mental health professionals and providers think. But sociologists and economists who tend not to look just at those in shelters see family homelessness as mostly a housing or income problem. In thinking about family homelessness, then, an initial question to ask is what construction of the problem we want.

\section{THE FUNCTION OF FAMILY SHELTERS}

Homeless family shelters act, in effect, as a mechanism that selects from the population of all poor families those who are worst off and least able or willing to make it on their own and puts them in one place to receive help. ${ }^{7}$ The initial growth in family shelters in the early to mid-1980s may have had to do with responding to the emergency needs of desperate families. But shelters have increasingly become a technique for selecting those families least able or willing to cope with their situations in order to provide them with social, medical, or psychological services as well as a roof. ${ }^{8}$

Figure 1 diagrams the argument. ${ }^{9}$ Homeless family shelters act to select and help poor families who are least able to cope (positive arrow). Shelters do this because of societal and governmental unwillingness or inability to deal with the deepening problems of poor families in general (bottom negative arrow). The greater the unwillingess or inability, the greater the emphasis on family shelters to select and treat the least able poor families (top negative arrow). The more subsidies to poor families are reduced, for example, the greater the reliance on homeless shelters to extract families that are worst off. The diagram also remakes a previous point: The more homeless shelters developed, the greater the number of poor families who will be found and given aid.

Another way of saying all this is that shelters cause homelessness. By their existence, shelters cause to be separated from the population of very poor families a group that is least able to cope with its problems. Shelters may also provide an avenue to resources that would otherwise be difficult or impossible to obtain (e.g., subsidized permanent housing).

To say that shelters cause homelessness is not to say that shelters create the problems homeless families face. They already have their problems: low incomes or welfare grants, lack of low-rent housing, overcrowded or substandard living conditions, drug addiction, and so forth. Rather, homeless shelters act like 
Family

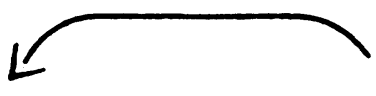

Shelters

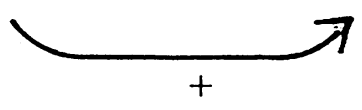

Selecting and Helping Families Least Able to Cope

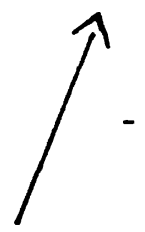

Societal/Government

Indifference to Deepening Problems of Poor Families

Figure 1: A Functional Explanation of Homeless Family Shelters

battered women's shelters, drawing out families with these problems so that they can be given help.

\section{WHY SHELTERS PERFORM THIS FUNCTION}

An important reason why shelters carry out this function is because the number of poor families unable to cope with their circumstances is a small proportion of the number of very poor families. In the face of an unwillingness or inability to deal with the deepening poverty of poor families in general, shelters provide a mechanism by which to screen the population to find out whose circumstances are so bad and whose resources and abilities are so weak that they may not survive without help (or who, at the least, need a respite from their living conditions).

The pool of families formally and economically "eligible" for shelters is in the millions. As Rossi observes, standards vary from city to city and sometimes within cities among the nonprofit organizations that run the shelters, so it is not easy to give a national estimate of what the size of the pool is. The Department of Housing and Urban Development (Nelson \& Khadduri, n.d., pp. 23-25) suggests that, in 1989, 2.1 million very-low-income families with children who rented their homes had "priority" housing problems, and this did not include displaced families who were homeless or doubled-up (p. 9) or who had the social, psychological, or physical problems that led some to shelter even if they did not have specific housing problems. ${ }^{10}$ Yet nationally there are probably no more than 60,000 families sheltered on any one night. ${ }^{11}$ 
To give a city-specific example, almost all families entering New York City shelters receive Aid to Families with Dependent Children (AFDC).$^{12}$ In mid1993, AFDC families numbered around 295,000, yet the number sheltered on any one night was about $5,700 .{ }^{13}$ Thus, at any one time, sheltered families are approximately $2 \%$ of the pool from which shelters draw.

Because the quality and requirements of shelter living establish a bottom rung of housing in an area, these numbers also suggest that sheltered families are among the worst-off families who are least able to manage problems and conditions that millions of other poor families do handle. ${ }^{14}$ In the next section, we consider why the number of sheltered families grew in the 1980s.

\section{A QUESTION OF TIMING}

Rossi's analysis of causes is, in effect, an analysis of why the number of homeless family shelters grew-from about 380 shelters in 1984 to around 2,000 by 1988 , an increase of over $400 \% .{ }^{15}$ But this analysis fails to address an often overlooked temporal mismatch. ${ }^{16}$ Almost all the trends Rossi cites began in the 1960 s or early 1970 s, with some peaking by the late 1970 s and early 1980 s, yet family homelessness exploded as a national problem in the mid-1980s and has continued to grow into the 1990s.

The structural transformation of the economy that hit poorly educated, unskilled, young minority men and women especially hard began in 1973. Too, as a result of increases in divorce and out-of-wedlock childbirth, the number of single-mother households began to rise in the 1960s. Similarly, the inflationary erosion of AFDC grants has been under way since 1970, with the bulk of the decline occurring by $1980 .{ }^{17}$

It is not clear why it took more than a decade for these changes to produce homeless families. It may have taken awhile for the converging and cumulative effects of the trends, catalyzed and augmented by the deep recession of 19821983 , to cross a threshold of deep poverty that prevented the formation of new households. Even as incomes of poor households declined through the 1970s and into the 1980 s, established families were probably able to hold onto their housing. But young, uneducated, poorly skilled males and females who were new to the job market were increasingly unable to make enough money to set up new households. For example, average earnings for the bottom $40 \%$ of all male high school dropouts, aged 20-29, fell from $\$ 5,816$ in 1973 to $\$ 1,922$ in 1986 (1990 dollars; Center for Labor Market Studies, n.d.). Partly as a result, when a new generation of young women began to have children they were less able to form two-parent households and had greater difficulty setting up their own households. Increasingly, they remained doubled-up with their parents, family, and friends, putting greater pressure on a household's space, finances, and social relations. These conditions deepened and became more widespread in the wake of the recession's destruction. Like the Red Cross after an earth- 
quake or hurricane, local welfare departments reported a surge of demand for shelter as the recession wore on.

Also in the mid-1980s, crack cocaine hit major urban areas with a vengeance. Between 1985 and 1989, emergency room episodes involving cocaine in the major SMSAs increased over $300 \%$, with increases over the previous year of $81 \%$ in 1986, 73\% in 1987, and 33\% in 1988 (Burt, 1992, p. 112). A 1992 New York City study found that $16 \%$ of (participating) sheltered women with children tested positive for cocaine (New York City Commission on the Homeless, 1992, p. C-4). And sheltered women in other cities may have the same problem. In six cities with over 1 million residents, about $52 \%$ of arrested women tested positive for cocaine during 1990; in New York's borough of Manhattan, $64 \%$ of women arrested tested positive (Flanagan \& Maguire, 1992, p. 473). Applying the ratio of these numbers to the New York City shelter data would suggest that about $13 \%$ of sheltered, female, homeless family heads in these cities would have tested positive for cocaine in 1990.

Skyrocketing foster care caseloads that coincided with the introduction of crack suggest an impact on family life that could also have led to homelessness. After increasing by perhaps $8 \%$ from the early 1960 s to the early 1980 s, the rate of substitute care rose $30 \%$ from the early 1980 s to $1989,22 \%$ between 1987 and 1989 (Testa, 1992, p. 28). Crack's cheap cost, short high, and violent effect make neglecting children, spending rent money on drugs, and alienating relatives and friends more likely. One result is that mothers lose custody of their children, thus increasing foster care. Another is the inability of mothers to keep their family housed either by itself or with friends and relatives, thereby increasing shelter use. Although the evidence we report is only correlational, it does suggest an explanation for the growth of family homelessness through the end of the 1980s that Rossi does not consider.

A third explanation for the mid-1980s surge is shelter development itself. Our analysis suggests that because a function of shelters is to select the poor families who are worst off, creating more shelters increases the opportunities to find such families. In addition, shelters provide better and safer housing compared with the run-down housing of drug-plagued, decaying neighborhoods in which some shelter users lived, and they offer greater independence for those in doubled-up housing.

Some of the trends Rossi describes created the conditions necessary for a national homeless problem. By the early 1980s, many single-parent families were poor in the extreme but perhaps not quite desperate. As time and the recession deepened their situation, as shelters were developed, and as crack hit, the explosion of homelessness was ignited.

\section{POLICY IMPLICATIONS: PROBLEMS WITH SHELTERS}

Our analysis raises the issue of whether we want to rely on shelters to help poor families that are worst off and least capable or willing to cope with their 
circumstances. A shelter policy does, after all, have severe problems. For one, specifically helping these families tends to give them benefits that similarly situated poor families who do not enter a homeless shelter do not get. Our welfare system already has misincentives of this sort: For example, mothers who stay on AFDC a long time have a greater chance of getting subsidized housing than do those who leave quickly. Do we want to add more misincentives?

Shelters also create a "safety net" set so low it threatens to cripple a family by the time it hits the net. Such a low safety net requires families, especially children, to experience levels of penury and pain they ought not to suffer. This is true not only of the fall to the shelters but sometimes of living in the shelters themselves. Congregating families with severe social and economic problems in one place can make it difficult to create the environment children need.

Third, because shelters provide a lower safety net than had previously existed, they create an opportunity for government to cut other subsidies to poor families. Most of the families affected would reduce expenses (if they could), rely on family and friends, or resort to using illegal sources of income. Only a small percentage of families experiencing, say, AFDC cuts, would show the visible effects of such cuts by entering a shelter.

\section{ALTERNATIVES TO SHELTERS: ROSSI'S PROPOSALS}

Whether or not we want to use shelters and whatever their problems, there is also the issue of whether there are feasible alternatives. Consider Rossi's proposals.

Rossi argues that the way to solve the homeless problem is to ignore the homeless specifically and to focus instead on the housing, income, and employment needs of poor families in general. He would, at a minimum, increase AFDC grants and would prefer an income maintenance program for all who are "vulnerable" to homelessness, but he would settle for subsidizing the rents of poor people through an expanded voucher program and for creating a program of aid to families with dependent adults. Long term, his suggestion is to provide young people with the skills that future job markets will demand and to provide public employment for all who ought to work but cannot find jobs.

Rossi's solutions flow directly from his analysis of the economic and housing causes of homelessness and would indeed achieve the permanent housing goal of shelters. But they ignore two fundamental truths: one about homelessness and the other about financing social programs in the 1990s. As we showed earlier, homelessness-entering a shelter-is a rare event, even among the very poor, and policy-making in the post-Reagan era of high budget deficits and antitax sentiment means that very little net new money will be available for new social initiatives.

The implications of these truths are profound. Rossi is correct in saying that the surest way to end the tragedy of family homelessness is to end the squeeze in rent and income plaguing the nation's poorest families. But because very few poor families enter a shelter, this is an extraordinarily expensive and inefficient 
way to find and help homeless families. Rossi found, for example, that only about $7 \%$ of extremely poor families enter a shelter over the course of a year. ${ }^{18}$ Even limiting the potential homeless pool to, say, those evicted by their landlord-a common event in the history of homeless families-does not help much. A New York City study of AFDC families who were evicted found that $75 \%$ stayed with family and friends until they found new housing (Towber \& Fleming, 1989, p. 6). They did not enter a shelter.

Restoring AFDC grants to their 1970 levels would cost perhaps $\$ 10$ billion, and only a small percentage of families receiving increased grants would have entered a shelter. Although the lost real-dollar value of AFDC has certainly worsened the lives of children and poor families and should be rectified on those grounds alone, it is difficult to argue for such a massive investment as a way to end homelessness.

Rossi's other income proposal, a universal rent subsidy for all poor persons, has the same but more extreme shortcomings. As this would go to all the poor, even fewer than $7 \%$ of those receiving the subsidy could be expected to have entered a shelter in the absence of such a program. But HUD estimates that a housing entitlement program for 5 million very-low-income families and nonelderly individuals that relied on vouchers to reduce renter burdens to $30 \%$ of adjusted income and that met HUD's voucher quality standards would cost $\$ 16.9$ billion per year (B. Zigas, personal communication, June 1992).

When confronted with both the cost and the inefficiency of these solutions, policy analysts inevitably ask why not provide subsidies just to families who have a high probability of entering a shelter and to families who actually do enter? Rossi implicitly makes the same argument by noting that it costs more than $\$ 13,000$ annually per family or $\$ 1,250$ per month to shelter a family. Instead, the argument asks, why not simply use the same amount of money to provide rental subsidies for permanent housing that would be of better quality than a shelter?

Although the logic of the argument seems impeccable on its face, it is flawed because it ignores the dynamic nature of shelter use. Like unemployment and participation in AFDC, most families are in shelters for a shorter time than a snapshot of shelter lengths of stay would show. In New York City, for example, about $30 \%$ of an entry cohort will leave in 30 days, $50 \%$ within 90 , and $70 \%$ within a year. But on any one day, over $80 \%$ of sheltered families will have been there at least 1 year (Berlin \& McAllister, 1992, p. 75).

The policy ramifications of this rate of turnover are significant. First, it means the $\$ 13,000$ spent to purchase a year's worth of homeless shelter actually houses about three families a year, not one. ${ }^{19}$ Also, if most homeless families leave shelters relatively quickly by finding permanent housing without formal assistance, as they do in New York City, providing rent subsidies or giving increased income or even permanent housing to these families would have no effect on the number of longer-term sheltered families. ${ }^{20}$

Third, and much more important, providing permanent housing, rent subsidies, or extra income assistance to short-stayers creates an incentive for families 
living, say, doubled up or in poor quality or unsubsidized housing to enter a shelter to obtain the subsidy. This entry effect can quickly overwhelm any effort to provide assistance to families already sheltered, resulting in an increase rather than a decrease in the number of sheltered families. In making subsidized housing available to homeless families, Massachusetts and St. Louis encountered an entry effects problem (Berlin \& McAllister, 1992, p. 76), and New York City's experience is instructive.

From June 1988 to April 1990, New York followed a target-efficient policy of providing permanent housing to families sheltered more than a year. Almost every family receiving housing had no other option and would have stayed sheltered without the subsidy. Because families had to wait one year to obtain permanent housing, the entry rate did not increase, as few families with other options were willing to remain in a homeless shelter for an entire year. As a result, the number of sheltered families declined over this time from 5,153 to 3,545 , with only a few hundred left in the nefarious welfare hotels of Jonathan Kozol's (1988) Rachel and Her Children.

But local political pressure and federal threats to withdraw funding forced the city to accelerate moving families out of welfare hotels. It continuously decreased the 1-year length of stay until the city reached the point where it was providing permanent housing to families sheltered as little as 3 months, sometimes less. One result was a $17.2 \%$ increase in the number of entering families (compared to a $2.6 \%$ increase the previous year; McAllister \& Berlin, 1993, p. 15) and a reopening of welfare hotels. By July 1993, the number of sheltered families had climbed above 5,700, with the number in welfare hotels back up to 1,152 .

That entering a shelter is a rare event for poor families argues for a targeted and thus more efficient strategy in allocating subsidies. But shelter dynamics and the risk of entry effects argue for either a length-of-stay requirement, as New York City had, or a universal approach, as Rossi counsels. Budget constraints suggest, however, that a universal approach would in reality be reduced to a more modest initial installment for only some of the poor. And the record indicates that, without targeting, families who become homeless would be less likely to gain access to these more modest subsidies (Burt, 1992, p. 96; Stegman, 1991, pp. 257-259). If policymakers have to decide how to allocate scarce resources to the poor so as to control the number of sheltered families, choices about which families to serve must be made. This means paying attention to shelter dynamics.

\section{SHELTER-BASED POLICIES: THE LIKELY FUTURE}

Realistically, it is very unlikely that more than $\$ 1$ billion will be made available in the near future to increase the number of affordable housing units or to increase AFDC grants. The expansion of the earned income tax credit in the 1993 budget and administration proposals for national health insurance greatly reduce chances for additional subsidies for low-income households. If 
the $\$ 1$ billion is to help homeless families, the only workable strategies are those that target the homeless.

One approach would be to mimic the response of most state and local governments. Because these governments are unable to fund a general response to the problems of poor families and do not want to attract homeless families, they try to address homelessness as a temporary problem (for example, see Berlin \& McAllister, 1992, pp. 85-86). In one incarnation, for instance, families more or less declare themselves homeless by seeking housing assistance from a welfare department. The agency provides a one-time subsidy for a very brief stay in a hotel, during which the mother leases a home, if she can. The agency then provides the security deposit and first month's rent, which cannot exceed a specified amount and is paid directly to the landlord. In this approach, a homeless family gets resources to find another home quickly but no additional help if it cannot find a home or cannot pay the third month's rent.

This policy avoids the problems of the shelter strategy, but because the subsidy only lasts two months, homeless families may face another crisis when the subsidy ends. It moves the problem elsewhere, placing more pressure on families to double up, to somehow make do on their own or to get assistance from other parts of the social welfare system. In fact, the latter is unlikely to happen, as witnessed by families entering shelters in the first place.

Also, in areas where public- or government-funded shelters already exist, service providers, social service professionals, and others have developed a political and economic commitment to them. A financial commitment from the Clinton administration for a shelter-based policy, which seems likely, would both strengthen this commitment and encourage it elsewhere. In these locales, the possibility of replacing shelters with a one-time subsidy seems remote.

If policymakers are to deal now with the problem of homeless families, the logical and fiscal problems of Rossi's proposals and the political and ethical difficulties of the one-time grant option suggest that some kind of shelter strategy is likely. Elsewhere, we detail a particular shelter-based strategy built around shelter dynamics (Berlin \& McAllister, 1992, pp. 86-89). This would provide permanent housing only to families who enter a transitional shelter, remain a specified time, and participate in shelter-provided services designed to prepare them for living independently. Families able to leave the shelter on their own before the wait for permanent housing is up would be assisted in leaving. This strategy would reduce and limit the number of long-term homeless families but would maintain a shelter system. It ameliorates the problem but does not end it.

That policy alternatives to shelters will tend to be too costly or unable to be put into place follows from the logic of our analysis. So, too, does the conclusion that family shelters are likely to remain. As shelters get chosen as the primary response for selecting and treating least able families, other responses become increasingly unlikely. This is because, in some sense, the strategy "works" (i.e., very bad off families are being found and given help) and because interests develop around maintaining this strategy (e.g., service providers). 
Also, shelters are chosen because, relative to other ways of obtaining the same end, they are cheaper. As many decry the cost of shelters, let us be clear about what is being more cheaply purchased: identification from among millions of poor families those who are, in some sense, worst off and least able to deal with their circumstances and the provision of a roof, food, and social, medical, and psychological services. Earlier, we showed how difficult identification is; the cost of providing these services without bringing the families into one place would obviously be prohibitive.

The combined impact of both implications leads to a final conclusion. Because they are cheaper and because other means are increasingly eschewed, shelters are here to stay.

\section{NOTES}

1. Indeed, when HUD's secretary visited a family shelter in New York City that provided private quarters and an abundance of social and medical services, he declared it a model of the kind of shelter he wanted to create nationwide (Dugger, 1993).

2. We are not saying that shelters explicitly seek out such families through, for example, outreach programs. At the individual level, it is the family that is self-selecting. Nor are we saying, at the individual or structural level, that shelters were initially established to find these families. As Stephen Jay Gould continually points out in a different context, current utility may say nothing about historical origins (see, e.g., Gould, 1991, pp. 114-115; for an exposition of the causal logic of this point in the kind of argument we are making, see Stinchcombe, 1968, pp. 101-106).

3. As we show in Figure 1, a device is needed because we are unwilling or unable to take on deepening poverty and its associated problems.

4. There are other ways to identify homeless families-see Burt (1992) or Marcuse (1990). But as far as public perception and government funding are concerned, families are not homeless unless they are in a shelter.

5. In his count of homeless people on Chicago streets in 1986 and 1987, Rossi (1989) did not find homeless families. Similarly, the Census Bureau's count in March 1990 did not yield many. In warmer locales, some families do live on the streets in cars and in other vehicles, but these seem to be very few. The test of our argument, of course, is whether sheltered families would start living on the street if our mental experiment to close the shelters were tried.

6. Bassuk and Rosenberg's (1988) cross-sectional study does not explicitly compare longerterm homeless with shorter-term or housed poor families. But as we later show, a cross section of a sheltered population will be dominated by longer-term families. Thus the differences they find in their comparison of sheltered and housed samples, as well as the differences between their findings and those of Knickman and Weitzman (1989), who sampled shelter requesters, suggest that longer-term families do have more severe problems than housed families or shorter-term families. That is, shelters service families that are "worst off."

7. Saying these families are least able to cope says nothing about why they are least able to cope (i.e., about whether or not it is "their fault"). See Note 6 for why we think these families are "worst off."

8. We are not saying these families need the services; they may just need housing. But shelter providers and others increasingly think families require these services and so make them available or insist on them.

9. We explicitly adopt Stinchcombe's (1968) depiction of functional explanation (see pp. 8091, 135-146). 
10. The battered women shelters are one example, as Rossi observes. Very-low-income families make less than $50 \%$ of the local area median. (The poverty level is about $40 \%$ of the local area median.) "Priority problems" are paying more than $50 \%$ of reported income for rent and utilities or having physical housing problems that are not easily fixed (Nelson \& Khadduri, n.d., p. 9).

11. But, as Rossi points out, the number of families sheltered is determined by the policies and resources of local governments and nonprofit agencies.

12. New York provides better data for the argument than do the national numbers as that city, unlike most other locales, has not had any formal limits on who can enter a shelter and how long they can stay. (There are informal constraints, such as the conditions of shelter living and the quality of the shelter.) Thus the national number of 60,000 sheltered homeless families is partly an artifact of the formal limits that different locales place on the number of families they will shelter. But in New York, the ratio of sheltered to poor families should more closely estimate the true fraction of poor families unable to cope to the population of poor families.

13. At the most, about 18,000 different families are sheltered in the course of the year. Thus the percentage of eligible families sheltered in a year is no greater than about $7 \%$.

14. See Note 6 for comparisons between homeless families and populations of poor families that further suggest that sheltered families are worst off.

15. Calculations are based on the HUD shelter surveys reported by Rossi.

16. Although the causal story that Rossi weaves sounds plausible, it is not clear that the numbers always add up. For example, the linchpin to his analysis is the effects of declining minority male employment on marriage formation. But perhaps only $20 \%$ of the growth of Black single-mother households since 1960 may be attributable to the decline in the pool of employed Black males (Sawhill, 1992, p. 158).

17. The welfare income that mothers have to spend has not decreased as much as Rossi states. From 1970 to 1992, median AFDC benefits for a mother of two children with no income did decline about $43 \%$, but the combined average AFDC and food stamp benefit fell only $25 \%$ over this time (U.S. House Committee on Ways and Means, 1992, pp. 641-643).

18. Rossi has determined that the income of extremely poor families is less than $51 \%$ of the poverty line or about $\$ 4,300$ in 1989 .

19. This is a national estimate, as Rossi states that the average shelter length of stay is 4 to 6 months. It is not clear whether this average is based (incorrectly) on point-in-time spell distributions or on completed spell distributions. If the former, it will tend to overestimate the length of stay. To hedge against this possibility we assume 4 months-the lower limit of Rossi's range.

20. One exception involves families who leave the shelters but return and do not leave again. This number might not be insignificant (data from New York City suggest that one third of families entering a shelter had been sheltered before) but may be small enough that target inefficiency remains an issue even for this group.

\section{REFERENCES}

Bassuk, E., \& Rosenberg, L. (1988). Why does family homelessness occur? A case control study. American Journal of Public Health, 7, 783-788.

Berlin, G., \& McAllister, W. (1992). Homelessness. In H. J. Aaron \& C. L. Schultze (Eds.), Setting domestic priorities (pp. 63-99). Washington, DC: Brookings Institution.

Blumer, H. (1971). Social problems as collective behavior. Social Problems, 3, 298-306.

Burt, M. (1992). Over the edge: The growth of homelessness in the 1980s. New York and Washington, DC: Russell Sage Foundation and Urban Institute.

Center for Labor Market Studies, Northeastern University. (n.d.). Current population survey: Public use tapes, March 1974 and 1987. Unpublished raw data.

Dugger, C. (1993, July 10). Leaming homelessness first hand. The New York Times, pp. 21, 23. 
Flanagan, T. J., \& Maguire, K. (Eds.). (1992). Bureau of Justice Statistics sourcebook of criminal justice statistics, 1991. Washington, DC: U.S. Department of Justice, Office of Justice Programs, Bureau of Justice Statistics.

Gould, S. J. (1991). Of kiwi eggs and the Liberty Bell. In Bully for brontosaurus: Reflections in natural history (pp. 109-123). New York: Norton.

Knickman, J. R., \& Weitzman, B. C. (1989). A study of homeless families in New York City: Final report, Vols. 2 and 3. New York: New York University Health Research Program.

Kozol, J. (1988). Rachel and her children. New York: Fawcett.

Marcuse, P. (1990). Homelessness and housing policy. In C.L.M. Canton (Ed.), Homelessness in America (pp. 138-159). New York: Oxford University Press.

McAllister, W., \& Berlin, G. (1993). Ending homelessness: Obvious solutions that won't work. Manuscript submitted for publication.

Nelson, K. P., \& Khadduri, J. (n.d.). To whom should limited housing resources be directed? Housing Policy Debate, 3(1), 1-55.

New York City Commission on the Homeless. (1992). The way home: A new direction in social policy. New York: Mayor's Office of the City of New York.

Rossi, P. (1989). Down and out in America: The origins of homelessness. Chicago: University of Chicago Press.

Sawhill, I. (1992). Young children and families. In H. J. Aaron \& C. L. Schultze (Eds.), Setting domestic priorities (pp. 147-184). Washington, DC: Brookings Institution.

Stegman, M. (1991). Remedies for homelessness: An analysis of potential housing policy and program responses. In J. H. Kryder-Coe (Ed.), Homeless children and youth: A new American dilemma (pp. 225-269). New Brunswick, NJ: Transaction.

Stinchcombe, A. L. (1968). Constructing social theories. New York: Harcourt, Brace \& World.

Testa, M. F. (1992). Conditions of risk for substitute care. Children and Youth Services Review, 1/2, 27-36.

Towber, R. I., \& Fleming, C. (1989). The housing alert program: A one year evaluation. New York: Human Resources Administration, City of New York.

U.S. House Committee on Ways and Means. (1992). Overview of entitlement programs, 1992 Green Book, background material and data on programs within the jurisdiction of the Committee on Ways and Means. Washington, DC: U.S. Government Printing Office. 